\title{
Evaluation of Bone Marrow Infiltration in Non-Neuropathic Gaucher Disease Patients with Use of Whole-Body MRI - A Retrospective Data Analysis
}

\section{Evaluierung der Knochenmarkinfiltration in non-neuropathischen Gaucher-Typ-1-Patienten mittels Ganzkörper-MRT, eine retrospektive Datenanalyse}

Authors

Affiliations

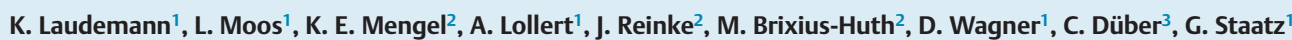

Section of Pediatric Radiology, Department of Diagnostic and Interventional Radiology, University Medical Center of the Johannes Gutenberg University, Mainz, Germany

Clinic for Metabolic Diseases, University Medical Center of the Johannes Gutenberg University, Mainz, Germany

3 Department of Diagnostic and Interventional Radiology, University Medical Center of the Johannes Gutenberg University Mainz, Germany

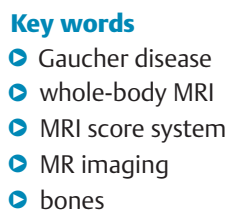

received 29.1.2015 accepted 15.6.2015

\section{Bibliography}

Dol http://dx.doi.org/ 10.1055/s-0035-1553362

Published online: 22.7 .2015 Fortschr Röntgenstr 2015; 187 : 1093-1098 ๔ Georg Thieme Verlag KG Stuttgart · New York . ISSN 1438-9029

\section{Correspondence}

\section{Prof. Gundula Staatz}

Sektion Pädiatrische Radiologie, Klinik und Poliklinik für Diagnostische und

Interventionelle Radiologie, Universitätsmedizin Mainz Langenbeckstr. 1

55131 Mainz

Germany

Tel.: $+49 / 6131 / 176927$

Fax: $+49 / 6131 / 176682$

staatz@uni-mainz.de

\section{Zusammenfassung \\ $\nabla$}

Ziel: Evaluierung der Ganzkörper-MRT für die Beurteilung der Knochenmarkinfiltration bei M.-Gaucher-Typ-1-Patienten unter Langzeit-Enzyme-Ersatz-Therapie (ERT).

Material und Methoden: Die retrospektive Datenanalyse umfasste insgesamt 38 Patienten, die in 2 Gruppen unterteilt wurden. Gruppe A: 10 wbl. Patienten, $9 \mathrm{ml}$. Patienten, 15-29 Jahre, Median 22 Jahre, Gruppe B: 11 wbl. Patienten, $8 \mathrm{ml}$. Patienten, 29-77 Jahre, Median 49 Jahre. Das Ganzkörper-MRT wurde bei allen Patienten mittels standardisierten Untersuchungsprotokolls durchgeführt. Zwei Radiologen werteten retrospektiv alle GK-MRT anhand von drei verschiedenen MRScores im Konsensus aus. Bestimmt wurden der Bone-Marrow-Burden-Score (BMB), der Düsseldorfer-Gaucher-Score (DGS) und die VertebraDisc-Ratio. Zudem wurde der Severity-Score-Index Typ 1 (GD-DS3) als ein nicht semiquantitativer klinischer Score angewandt.

Ergebnisse: Für beide Gruppen lagen die ermittelten MR-Scores im niedrig bis moderat pathologischen Bereich. Die statistische Auswertung der MR-Scores ergab keinen signifikanten Unterschied zwischen beiden Gruppen. Der Median für Gruppe A/Gruppe B lag für den BMB-Score bei 7,00/9,00 ( $p=0,07)$, für den DGS-Score bei $4,00 / 3,00(p=0,062)$ und für den VDR-Score bei $1,54 / 1,62(p=0,267)$. Im Gegensatz dazu war der GD-DS3-Score statistisch signifikant unterschiedlich zwischen beiden Gruppen (1,6/3,9, $\mathrm{p}=0,000)$ und Knochenkomplikationen wurden nur in Gruppe B gefunden.

Schlussfolgerung: Knochenmarkbeteiligung und die für die Gaucher-Krankheit typischen klinischen Manifestationen sind bei frühzeitiger Langzeit-ERT auf ein Minimum reduziert. Die angewandten MR-Scores sind ein hilfreiches Mittel für das Monitoring der Knochenmarkinfiltration bei älteren Gaucher-Typ-1-Patienten. Pathologische

\section{Abstract \\ $\nabla$}

Purpose: To evaluate whole-body magnetic resonance imaging (WB-MRI) for the assessment of bone marrow infiltration in patients with confirmed Gaucher disease type 1 under long-term enzyme replacement therapy (ERT).

Materials and Methods: This retrospective data analysis included 38 patients in two subgroups. Group A: 10 females, 9 males, 15 - 29 years, mean age 22 years and Group B: 11 females, 8 males, 29 - 77 years, mean age 49 years, all treated with alglucerase or imiglucerase for at least 12.5 years. Whole-body MRI was carried out in all patients using a standard MRI protocol. Two radiologists assessed all MR images retrospectively with the use of three different MRI score systems: The bone marrow burden (BMB) score, the Düsseldorf-Gaucher score (DGS) and the vertebra disc ratio (VDR). As a clinical component, severity score index type 1 (GD-DS3) was determined.

Results: In both groups the MR scores showed low to moderate pathologic levels but no statistically significant difference was found between both groups. The median scores in group A/group B were 7.00/9.00 for the BMB score $(p=0.07), 4.00 /$ 3.00 for the DGS score $(\mathrm{p}=0.062)$ and $1.54 / 1.62$ for the VDR score $(p=0.267)$. The GD-DS3 score was statistically significantly different between both groups (1.6/3.9, p=0.000) and osseous Gaucher disease complications were only found in group B. Conclusion: Bone marrow involvement and typical clinical manifestations are reduced to a minimum, when ERT starts immediately after the confirmed diagnosis of Gaucher disease type 1. The applied MR scores are useful markers to control bone marrow infiltration under enzyme replacement therapy in older patients. Pathologic MR scores in young patients may reflect postponed fat conversion of the juvenile bone marrow. This issue has to be examined in further studies. 
MR-Scores bei jungen Gaucher-Patienten weisen möglicherweise auf eine verzögerte Fettmarkkonvertierung des jungen Knochenmarks hin.

Kernaussagen:

- Das Ganzkörper-MRT ist hilfreich für das Staging von GaucherTyp-1-Patienten.

- Knochenkomplikationen sind bei frühzeitigem Beginn einer Langzeit-ERT auf ein Minimum reduziert.

- Die etablierten MR-Scores müssen zukünftig für junge Gaucher-Patienten angepasst werden.
Key Points:

- Whole-body MRI is valuable for the staging of Gaucher disease type 1.

- Osseous complications are reduced to a minimum in early treated patients.

- MR score systems have to be adjusted in young Gaucher patients.

Citation Format:

- Laudemann K, Moos L, Mengel KE et al. Evaluation of Bone Marrow Infiltration in Non-Neuropathic Gaucher Disease Patients with Use of Whole-Body MRI - A Retrospective Data Analysis. Fortschr Röntgenstr 2015; 187: 1093-1098

\section{Introduction}

$\nabla$

Gaucher disease is an autosomal recessive, lysosomal storage disorder, which is caused by the abnormal activity of the lysosomal hydrolase- $\beta$-glucosidase, leading to the accumulation of glucocerebroside (glucosylceramides) in the lysosomes of the macrophages, the so-called "Gaucher cells" [1]. Those cells accumulate especially in the bone marrow, the spleen and the liver.

Gaucher disease has traditionally been divided into three clinical subtypes [2]: neuropathic types 2 and 3 and non-neuropathic type 1 , which is most common. Typical clinical findings are hepatosplenomegaly, pancytopenia, hypermetabolism and severe pain on movement. The osseous involvement, causing skeletal pain, cor- responds to the infiltration of Gaucher cells into the bone marrow. Bone marrow involvement ( $\bullet$ Fig. 1) may result in diffuse osseous changes, such as osteopenia and focal lesions such as lytic zones, osteonecrosis, bone infarction or long bone deformity (Erlenmeyer flask deformity).

Before enzyme replacement therapy (ERT) was established in the 1990 s, patients were only clinically controlled and treated with regard to their symptoms [3]. In our university hospital the dosage of enzyme replacement therapy (ERT) is monitored and if necessary adjusted according to the laboratory findings, especially the increase of chitotriosidase [2]. Furthermore, the individually adapted ERT dosage depends on the grading of bone
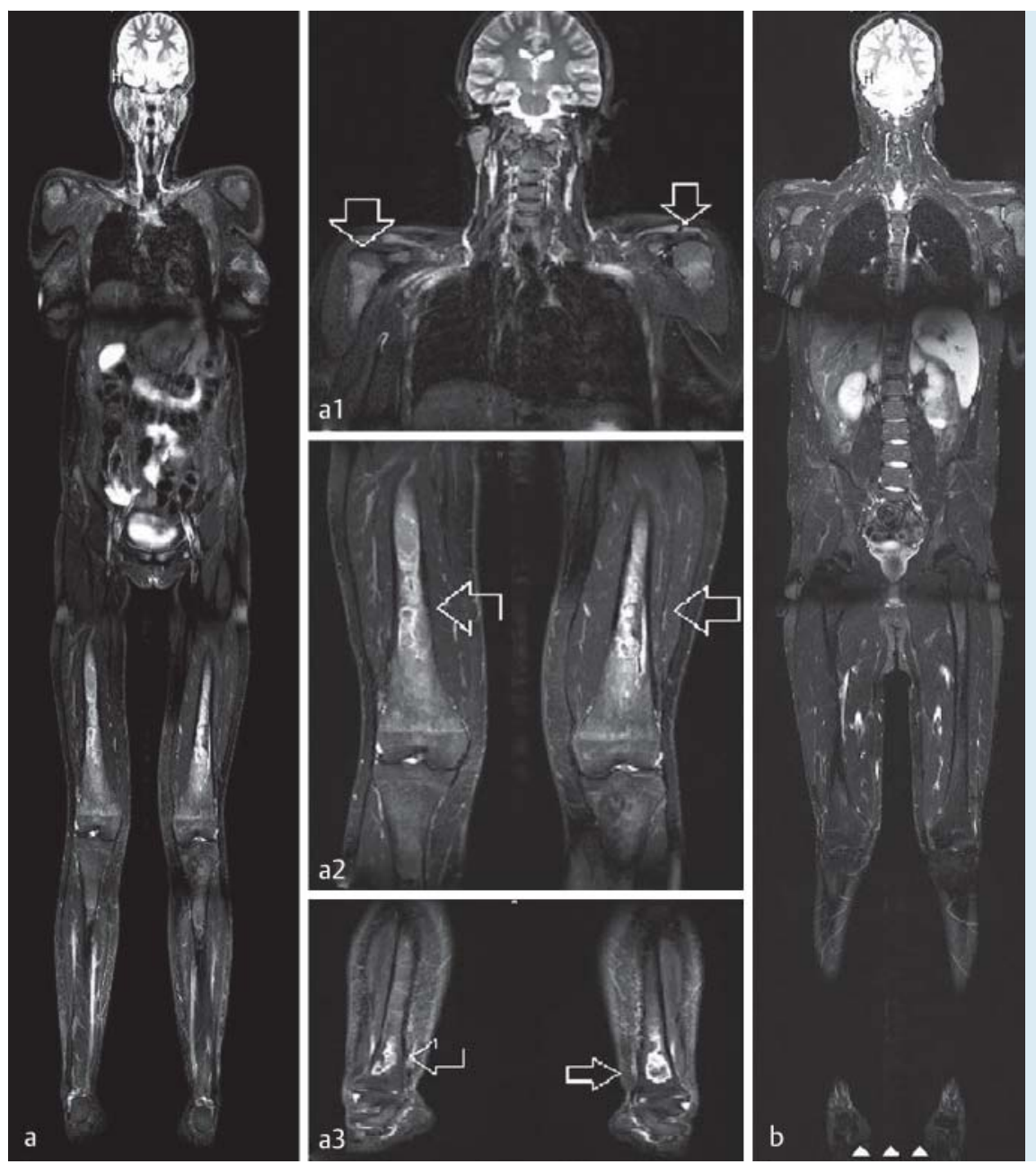

Fig. 1 a 35 yrs, female, group B. Whole-body MRI, coronal TIRM sequence. Multifocal bone marrow Gaucher infiltrations in the proximal humerus a1, the lumbar spine and the lower extremities a2, a3, inclusive Gaucher infiltration of the distal femoral epiphysis. Extensive medullar cavity infarctions in both femoral diaphysis a2, and distal tibial metaphysis a3. b 22 yrs., male, group A. Normal wholebody MRI image.

Abb. 1 a 35J., weiblich, Gruppe B. GanzkörperMRT, koronare TIRM-Sequenz. Multifokale Knochenmarkinfiltration bei M. Gaucher der proximalen Humeri a1, Lendenwirbelsäule und der untere Extremitäten a2, a3, einschließlich Gaucher-Infiltration der distalen Femurepiphysen a2. Ausgedehnte Knocheninfarkte in den Femurdiaphysen a2 und in den distalen Tibiametaphysen a3. b 22 J., weiblich, Gruppe A. Unauffälliges Ganzkörper-MRT. 
Table 1 GD-S3 scoring system.

Tab. 1 GD-S3 scoring system.

\begin{tabular}{|c|c|c|c|c|c|c|c|c|c|c|c|c|c|c|}
\hline \multirow[t]{2}{*}{ domain } & \multirow[t]{2}{*}{ item } & \multicolumn{11}{|c|}{ score points } & \multirow{2}{*}{$\begin{array}{l}\max \\
\text { score }\end{array}$} & \multirow{2}{*}{$\begin{array}{l}\text { domain } \\
\text { score }\end{array}$} \\
\hline & & 0 & 1 & 2 & 3 & 4 & 5 & 6 & 7 & 8 & 9 & 10 & & \\
\hline \multirow[t]{6}{*}{ bone } & $\begin{array}{l}\text { AVN, } \\
\text { path. fractures }\end{array}$ & no & & & & & & & & yes & & & 8 & \multirow[t]{6}{*}{8.0} \\
\hline & pain & & & & & & & & & & & & 10 & \\
\hline & bone crisis & $0-1$ & & $\geq$ & & & & & & & & & 2 & \\
\hline & BMB & $0-4$ & & & & & & & & $5-8$ & & & 10 & \\
\hline & \multirow{2}{*}{ BMD } & \multirow{2}{*}{\multicolumn{2}{|c|}{$>-1$}} & $>-2$ & & & & & & & & & \multirow[t]{2}{*}{10} & \\
\hline & & & & $\leq-1$ & & & & & & & & & & \\
\hline \multirow[t]{3}{*}{ haematological } & thromb & $\geq 120$ & & $21-119$ & & & $<20$ & & & & & & 5 & \multirow[t]{3}{*}{6.0} \\
\hline & bleeding & no/mild & & mod. & & & & & & sev. & & & 8 & \\
\hline & $\mathrm{Hb}$ & $>12$ & & $8-12$ & & & $<8$ & & & & & & 5 & \\
\hline \multirow[t]{3}{*}{ visceral } & spleen & $<5 x$ & & $5-15 x$ & & & $>15 x$ & & & & & & 5 & \multirow[t]{3}{*}{5.0} \\
\hline & liver & $\leq 2.5 x$ & & $>2.5 x$ & & & & & & & & & 2 & \\
\hline & lung & no & & & & & & & & yes & & & 8 & \\
\hline total & & & & & & & & & & & & & & 19.0 \\
\hline
\end{tabular}

Source: Weinreb N, et al. Gen Med 2010; 12: 44 - 51.

marrow infiltration, as determined by MRI, which underlines the clinical significance of MR imaging in Gaucher patients. [2]

The aim of our data analysis was to evaluate whole-body magnetic resonance imaging (MRI) as an imaging and monitoring tool for the detection of typical osseous changes in patients suffering from Gaucher disease type1, and to quantify the bone marrow infiltration in patients on long-term ERT using different MRI score systems.

In contrast to other studies known in the literature, we wanted to retrospectively evaluate the long-term outcome of pediatric patients treated early with treatment initiation before the age of 10 years, in contrast to an adult patient group, in which treatment initiation with ERT started much later in life.

\section{Patients and Methods}

Whole-body MRI in 38 patients (21 female, 17 male, aged 15 - 77 years) with confirmed Gaucher disease type 1 were retrospectively analyzed. Therefore, the patient collective was divided into two subgroups with 19 patients each:

- Group A (10 female, 9 male, aged 15 - 29 years; mean age: 22 years) was initially diagnosed at an average age of six years.

- Group B (11 female, 8 male, aged 29 - 77 years; mean age: 49 years), suffering from severe bone marrow disease, was initially diagnosed at an average age of 27 years.

For enzyme replacement therapy (ERT) all patients were treated with alglucerase (Ceredase ${ }^{\circledR}$, Genzyme Corporation, Cambridge, MA) or imiglucerase (Cerezyme ${ }^{\circledR}$, Genzyme Corporation, Cambridge, MA) for at least 12.5 years. All patients received individually adapted doses every second week. 7 patients (1 in group A; 6 in group B) switched from imiglucerase to velaglucerase $\left(\right.$ VPRIV $\left.^{\circledR}\right)$ therapy during the last 4 years of ERT treatment. Before the change in treatment, those 7 patients received alglucerase or imiglucerase for an average time of 14 years.

Whole-body MRI examinations were performed in 38 patients on a 1.5 Tesla MRI scanner (Magnetom Avanto, 1.5 T, Siemens, Erlangen Germany) using a standard MRI protocol. Coronal STIR and T1TSE sequences were used for whole-body imaging and sagittal
TIRM, T2-TSE and T1-TSE sequences for the evaluation of the lumbar spine.

The following sequence parameters were applied:

1. Coronal TIRM: TR $5370-10.400 \mathrm{~ms}$, TE $57 \mathrm{~ms}$, TI $160 \mathrm{~ms}$, slice thickness $6 \mathrm{~mm}$, slice gap $10 \mathrm{~mm}$, flip angle $150^{\circ}$, FOV $450 \mathrm{~mm}$, scan matrix 384 , reconstruction matrix $512,12 \mathrm{~min}$ and $26 \mathrm{~s}$ duration.

2. Coronal T1-TSE: TR $486 \mathrm{~ms}$, TE $9.5 \mathrm{~ms}$, slice thickness $6 \mathrm{~mm}$, slice gap $10 \mathrm{~mm}$, flip angle $150^{\circ}$, FOV $450 \mathrm{~mm}$, scan matrix 448 , reconstruction matrix $512,13 \mathrm{~min}$ and 33 s duration.

3. Sagittal TIRM: TR $3500 \mathrm{~ms}$, TE $37 \mathrm{~ms}$, TI $160 \mathrm{~ms}$, slice thickness $4 \mathrm{~mm}$, slice gap $10 \mathrm{~mm}$, flip angle $150^{\circ}$, FOV $300 \mathrm{~mm}$, scan matrix 320, reconstruction matrix 512, $3 \mathrm{~min}$ and 49 s duration.

4. Sagittal T2-TSE: TR $3500 \mathrm{~ms}$, TE $91 \mathrm{~ms}$, slice thickness $4 \mathrm{~mm}$, slice gap $10 \mathrm{~mm}$, flip angle $150^{\circ}$, FOV $300 \mathrm{~mm}$, scan matrix 512 , reconstruction matrix 512, 2 min and 18 s duration.

5. Sagittal T1-TSE: TR $767 \mathrm{~ms}$, TE $11 \mathrm{~ms}$, slice thickness $4 \mathrm{~mm}$, slice gap $10 \mathrm{~mm}$, flip angle $150^{\circ}$, FOV $300 \mathrm{~mm}$, scan matrix 512, reconstruction matrix 512, $3 \mathrm{~min}$ and $12 \mathrm{~s}$ duration.

All MR images were assessed by two experienced radiologists in consensus.

The whole-body MR images were evaluated regarding the presence of diffuse or focal bone lesions (osteonecrosis, bone infarction, lytic zones) of the lower extremities (femora, tibiae, epiphyses, femoral heads) and the humerus.

For the quantification of the bone marrow infiltration by Gaucher cells, the following semi-quantitative scoring systems were used:

- The bone marrow burden score (BMB), adopted by Maas et al. [4], indirectly evaluates the bone marrow infiltration of Gaucher cells in the femora and the lumbar spine by means of a visual interpretation of signal intensity.

- The Düsseldorf-Gaucher score (DGS) by Poll et al. [5] is a defined scoring system for the lower extremities and for differentiating between A-patterns (homogeneous) and B-patterns (non-homogenous) of Gaucher cell bone marrow infiltration (॰ Fig. 2).

- The vertebra disc ratio score (VDR) by Vlieger et. al. [6] evaluates the average signal intensity ratio of the L3 vertebra in relation to the healthy L3 / L4 disc on T1-weighted images. 


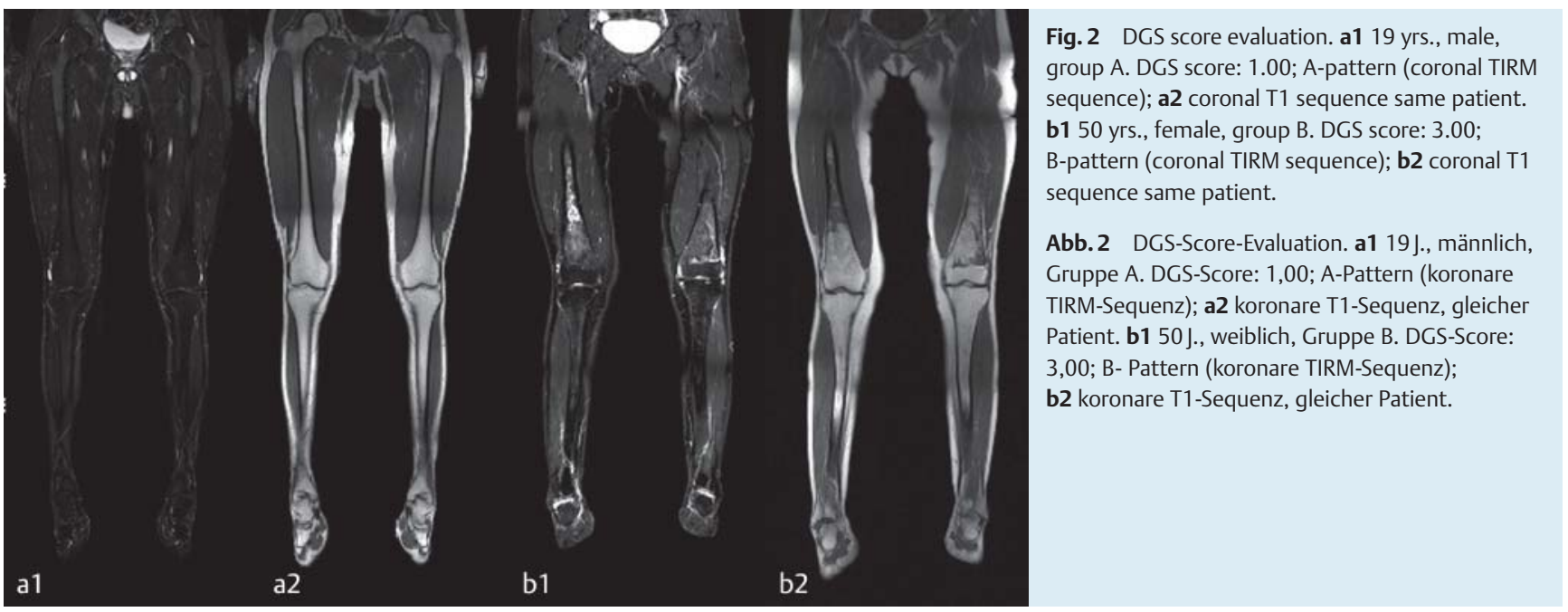

- The Gaucher disease type 1 severity scoring system (GD-DS3) by Weinreb et. al. [7] is a clinical test, which was obtained twice for each patient, once with the inclusion of the BMB score and once without it. It is based on the experience of many physicians and describes three domains (osseous, hematologic, and visceral) with several assessments ( $\bullet$ Table 1). No patient suffered from growth retardation in either patient group.

Statistical data evaluation was performed with the use of the IBM $^{\circledR}$ SPSS $^{\circledR}$ Statistics 20 software (copyright IBM Corporation 1989, 2011). The evaluation of the semi-quantitative score systems was conducted by descriptive statistics with explorative data analysis. Differences between the groups were analyzed by the non-parametric Mann- Whitney-U test.

\section{Results}

$\nabla$

Osseous lesions were found in a total of 7 patients, all belonging to group B. 4 of these patients showed more than one osseous lesion located in the tibial diaphysis and metaphysis (5x), the proximal/distal tibial epiphyses ( $1 \mathrm{x})$, the femoral diaphysis and metaphysis (5x), the distal femoral epiphysis (2x), and the femoral head ( $3 \mathrm{x})$. Humeral involvement was detected in 2 patients. 3 patients had visceral involvement (gaucheroma - spleen, liver).

\section{BMB score:}

For all evaluated patients, the BMB score median was 8.00 (group A: 7.00; group B: 9.00). The BMB score median for the lumbar spine was 4.00 in both groups and for the femora 3.00 in group A and 4.00 in group $B$.

This means that the BMB score for group $A$ is definitely on the moderate level, whereas the BMB score for group $B$ is at the threshold to the severe level (low level: 0-4; moderate: 5-8; high: 9-15).

\section{DGS score:}

For all patients the median is 3.00 (group A: 4.00; group B: 3.00 ). For both groups the DGS score is therefore within the lower level $(0-5) .7$ group B patients displayed a B-pattern in the DGS, meaning heterogeneous bone marrow infiltration ( $\bullet$ Fig. 2 ).

\section{VDR score:}

For all patients the median VDR score is 1.54 (group A: 1.54; group $\mathrm{B}: 1.62)$, which is concordant with a long-treated patient $(1.70 \pm 0.33)$.

In group A the VDR scores indicated normal values in 4 patients ( $\bullet$ Fig. 3), VDR values equivalent to long-treated patients in 7 cases and VDR values equivalent to untreated patients in 8 cases. In group B 4 patients showed normal VDR values, 9 patients had VDR scores of long-treated patients and 6 patients revealed VDR values equivalent to untreated patients ( $\bullet$ Fig. 3 ).

\section{GD-DS score:}

For all patients, the median GD-DS score was 2.0 with the BMB score included (group A: 1.6; group B: 3.9 ) and with the BMB score excluded 0.50 (group A: 0.0; group B: 2.50 ).

For both groups, there was a high statistical significance in the GD-DS3 score $(p=0.000)$ regardless of whether the BMB score is excluded or included. All differences between the groups were analyzed by the non-parametric Mann-Whitney-U test with the result being that no statistical significance was found in the objective scoring systems (BMB score: $\mathrm{p}=0.070$; $\mathrm{DGS}$ : $\mathrm{p}=0.062$; VDR score: $\mathrm{p}=0.267$ ) ( $\odot$ Table 2 ).

\section{Discussion \\ $\nabla$}

Gaucher disease is a rare lysosomal disorder, which has been able to be successfully treated with ERT for approximately 20 years. Previous studies demonstrated that ERT administered to adult patients reduces liver and spleen volume as well as abnormal bone infiltration, which subsequently results in fewer clinical symptoms [8-10]. Today Gaucher disease is diagnosed in early childhood and it is of vital importance to establish effective ERT especially at this early stage of the disease. As a result, rapid progress of the disease, which leads to retarded growth and delayed puberty in about $50 \%$ of the affected children, can be prevented $[11,12]$.

Our analysis included only patients with confirmed Gaucher type 1 disease and concentrated on the analysis of bone marrow involvement in patients diagnosed early with ERT starting immediately after diagnosis (group A). We compared these patients with an adult Gaucher type 1 group, which was also treated with longterm ERT, but with a later beginning of treatment at an adult stage (group B). 

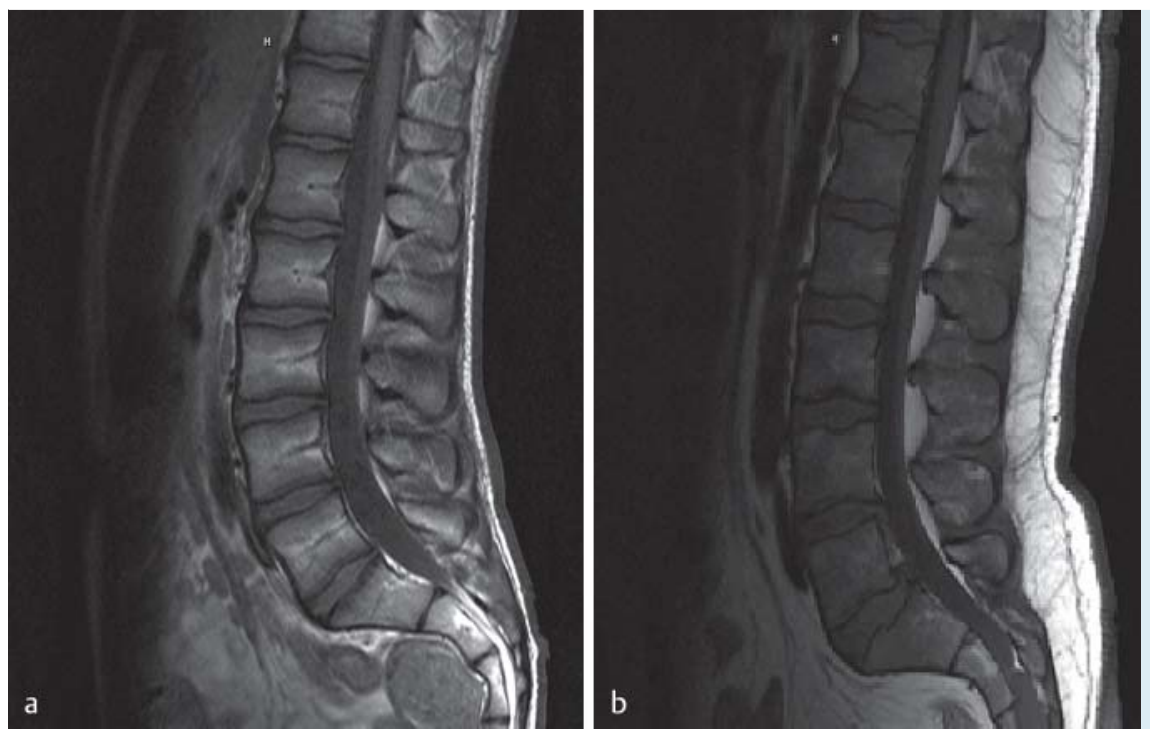

Fig. 3 VDR score a 19 yrs., male, group A. VDR score: 2.01; normal lumbar spine value (T1-weighted image); b 29 yrs., male, group B. VDR score: 1.41; pathological lumbar spine value ( $\mathrm{T} 1$-weighted image).

Abb. 3 VDR-Score a 19]., männlich, Gruppe A. VDR- Score: 2.01; normaler LendenwirbelsäulenWert (T1-gewichtetes Bild); b 29 J., männlich, Gruppe B. VDR-Score: 1,41, pathologischer Lendenwirbelsäulen-Wert (T1-gewichtetes Bild).

Table 2 Summary of the assessed MR scores in both Gaucher type 1 patient groups.

Tab. 2 Zusammenfassung der MR Scores beider Gruppen.

\begin{tabular}{|llll|}
\hline score (Median) & group A & group B & p-value \\
\hline BMB & 7.00 & 9.00 & 0.070 \\
\hline DGS & 4.00 & 3.00 & 0.062 \\
\hline VDR & 1.54 & 1.62 & 0.267 \\
\hline GD-DS3 & $1.6 /-$ BMB: 0.00 & $3.90 /-$ BMB: 2.50 & 0.000 \\
\hline $\begin{array}{l}\text { patients with } \\
\text { osseous compli- } \\
\text { cations }\end{array}$ & 0 & 7 & \\
\hline
\end{tabular}

Score classifications:

- BMB score: 0 - 4 (mild), 5 - 8 (moderate), 9-15 (heavy)

- DGS score: 1 - 6 (low), 7 - 8 (high) / type A \& B-pattern

- VDR score: $1.9 \pm 0.30$ (normal), $1.29 \pm 0.31$ (untreated pat.), 1.7. \pm 0.33 (long-treated pat.)

Group A showed no typical osseous Gaucher complications, such as osteonecrosis or bone infarction, but moderate pathologic MRI values in the BMB, DGS and VDR scores. Adult group B displayed major skeletal involvement and moderate to severe pathologic MRI score values. This indicates that early ERT is important for the prevention of osseous complications and irreversible skeletal damage.

With the beginning of long-time ERT, it was essential to find a widely applicable, reliable method to assess skeletal complications (i.e., infarctions, focal lesions, bone marrow conversion) in Gaucher disease. As widely known, MRI is the most sensitive method for detecting bone marrow infiltration in various diseases. Furthermore, many MRI-based quantitative measurement methods for the evaluation of bone marrow infiltration in Gaucher patients were established, for example, nuclear magnetic resonance spectroscopy, with $\mathrm{T} 1$ relaxation time calculations, or DIXON quantitative chemical shift imaging (DIXON-QCSI). The DIXON-QSCI technique $[8,13]$ directly measures the medullar fat fraction $[14,15]$. However, compared to whole-body MRI, Dixon QCSI is not included in the standard packages of sequences on MR scanners and there are only a few centers in Europe, like AMC in Amsterdam, the Netherlands) offering this technique [14, 16, 17]. Until now, the only clinical whole-body MRI study in a co-

hort of Gaucher patients was presented by Poll et al. [18] dealing with the bone marrow involvement of the lumbar spine, the lower extremities and the humeral bones.

For the evaluation of the BMB, DGS, VDR scores, our patient collective was subdivided into two groups. Those secondary semiquantitative score systems can be applied almost simultaneously with the whole-body MRI examination. Previous studies proved those score systems to be reliable regarding the assessment of osseous involvement and bone marrow alterations in adults under ERT. The study by Maas et al. (2003) demonstrated a significant correlation between the BMB score and the DIXON-QCSI [2]. The DGS and VDR scores were used in several other studies [5, 6, 19] and both score systems showed viability for radiological follow-up of bone marrow infiltration in Gaucher disease.

In our study, all objective MRI score systems did not demonstrate statistical significance in the Mann-Whitney-U Test between the examined groups. Our practical experience shows us that the $\mathrm{BMB}$ and the DGS scores are especially useful for patients with characteristic Gaucher symptoms under long-term ERT, especially in order to document bone marrow changes in the lower extremities in long-term follow-ups. For group B, a weak statistical correlation was found between the B-pattern and a higher risk for typical Gaucher bone complications.

However, the usefulness of these score systems was not confirmed for all patient collectives. The clinical status of group A patients is not congruent with the score system outcomes. But why do the results from the semi-quantitative MRI score systems of early treated group A patients diverge greatly from their actual clinical status?

At this point, it is of vital importance to define in MRI what normal bone marrow morphology is in a population of young, healthy subjects in comparison to young Gaucher patients treated early without any clinical signs. Due to the high amount of red bone marrow in young healthy subjects, the MRI signal characteristics are identical when compared to young Gaucher disease patients.

With regard to the applied MR field strength of 1.5 Tesla in our study, we do not believe that the use of a 3 Tesla MR system would have changed the results of the presented MR score findings in our Gaucher patients. Although the signal-to-noise ratio is higher for 3 Tesla MR scanners compared to 1.5 Tesla MRI sys- 
tems, the used MRI scores are not affected due to the measurement of signal characteristics within the same image.

Statistical significance in the non-parametric Mann-Whitney-U test was, however, found in the clinical GD-DS3 score in both study groups, even if the GD-DS3 included the objective parameters of the BMB score. This means that the clinical relevance and usefulness of this score is given for both groups. Therefore, we consider that the GD-DS3 score is valuable for the routine diagnostics of Gaucher disease.

Compared to other studies, our present study revealed similar results for the MRI score systems as described before. For example, the study by Maas et al. [4] demonstrated a maximum improvement of 9 points in the BMB score in Gaucher patients under ERT. The study by Robertson et al. [20] revealed that the BMB score assesses the degree of skeletal involvement. Both studies [4, 20] confirmed the BMB score to be an optimal follow-up bone marrow response parameter in adult Gaucher patients. A previous study by Poll et al. [18] demonstrated that a high DGS or B-pattern morphology significantly correlates with avascular necrosis or other bone complications.

The VDR score is especially valuable for longitudinal follow-up studies of bone marrow measurements [6]. However, the VDR interpretation is subject to specific difficulties, arising from the influences of age and daily fluctuations in the water content of the intervertebral disk $[20,22,23]$. It can be stated that the VDR interpretation shows better reliability for younger patients, because they do not suffer from vertebral disk degeneration as seen in older patients.

\section{Conclusion}

$\nabla$

Whole-body MRI is a recommendable method to assess Gaucher cell bone marrow infiltration especially in adult Gaucher patients. Our whole-body MRI analysis demonstrated that young Gaucher patients on long-term ERT who were diagnosed and treated early showed no typical osseous complications. In the case of a good response to treatment, de-escalation therapy was conducted implying a reduction of the ERT doses.

The moderate pathologic MRI score values in the BMB, DGS and VDR score systems, found in the young Gaucher patient group, are similar to the known MRI signal characteristics of bone marrow in healthy young subjects and do not reflect the extent of bone involvement in Gaucher disease. Obviously, due to the high amount of red bone marrow in young Gaucher patients, the current MRI score systems are not suitable for this patient cohort, so that we propose that they have to be adjusted. Further MRI studies will try to define how normal bone marrow morphology in a young, healthy population can be differentiated from a young Gaucher patient treated early without any clinical symptoms.

\section{Acknowledgment}

$\nabla$

The Retrospective data analysis was supported by Genzyme a Sanofi company.

The results of the study are part of the thesis of Larissa Moos.

\section{Literatur}

1 Brady RO, Kanfer JN, Shapiro D. Metabolism of glucocerebrosides. II. evidence of an enzymatic deficiency in gaucher's disease. Biochemical and biophysical research communications 1965; 18: $221-225$

2 Leitlinien zu Morbus Gaucher. - anerkannt in 2006 [Internet].[cited 26.03.2014]. Available from: http://www.ggd-ev.de/leitlinien-zu-morbus-gaucher/

3 Zimran A. How I treat Gaucher disease. Blood 2011; 118: 1463 - 1671

4 Maas M, van Kuijk C, Stoker J et al. Quantification of Bone Involvement in Gaucher Disease: MR Imaging Bone Marrow Burden Score as an Alternative to Dixon Quantitative Chemical Shift MR Imaging-Initial Experience. Radiology 2003; 229: 554-561

5 Poll LW, Willers R, Häussinger D et al. MRT der Knochenmarkverändungen bei 63 Patienten mit Morbus Gaucher Typ I. Fortschr Röntgenstr 2010; 182: 979-985

6 Vlieger EJP, Maas M, Akkerman EM et al. Vertebra disc ratio as a parameter for bone marrow involvement and its application in Gaucher disease. Journal of computer assisted tomography 2002; 26: 843-848

7 Weinreb NJ, Cappellini MD, Cox TM et al. A validated disease severity scoring system for adults with type 1 Gaucher disease. Genetics in Medicine 2009; 12: 44-51

8 Maas M, Hollak CE, Akkerman EM et al. Quantification of skeletal involvement in adults with type I Gaucher's disease: fat fraction measured by Dixon quantitative chemical shift imaging as a valid parameter. Am J Roentgenol 2002; 179: 961 - 965

9 Poll LW, Koch JA, Willers $R$ et al. Correlation of bone marrow response with hematological, biochemical, and visceral responses to enzyme replacement therapy of nonneuropathic (type 1) Gaucher disease in 30 adult patients. Blood cells, molecules \& diseases 2002; 28: 209-220

10 Shah $U$, Nadeem N, Husen $Y$ et al. Imiglucerase treatment in Gaucher's disease. Journal of Ayub Medical College, Abbottabad: JAMC 2007; 19: $56-59$

11 Zevin S, Abrahamov A, Hadas-Halpern I et al. Adult-type Gaucher disease in children: genetics, clinical features and enzyme replacement therapy. The Quarterly journal of medicine 1993; 86: 565-573

12 Kaplan P, Mazur A, Manor $O$ et al. Acceleration of retarded growth in children with Gaucher disease after treatment with alglucerase. The Journal of pediatrics 1996; 129: 149-153

13 Johnson LA, Hoppel BE, Gerard EL et al. Quantitative chemical shift imaging of vertebral bone marrow in patients with Gaucher disease. Radiology 1992; 182: 451 - 455

14 Maas M, Poll LW, Terk MR. Imaging and quantifying skeletal involvement in Gaucher disease. British Journal of Radiology 2002; 75: A13 - A24

15 Mikosch P, Hughes D. An overview on bone manifestations in Gaucher disease. Wiener medizinische Wochenschrift (1946) 2010; 160: 609624

16 Poll LW, Maas M, Terk MR et al. Response of Gaucher bone disease to enzyme replacement therapy. The British journal of radiology 2002; 75: A25-A36

17 Vom DahlS, Poll L, Di Rocco M et al. Evidence-based recommendations for monitoring bone disease and the response to enzyme replacement therapy in Gaucher patients*. Current Medical Research and Opinion 2006; 22: $1045-1064$

18 Poll LW, Cox ML, Godehardt E et al. Whole body MRI in type I Gaucher patients: Evaluation of skeletal involvement. Blood Cells, Molecules, and Diseases 2011; 46: 53-59

19 Poll LW, Koch JA, Vom Dahl S et al. Magnetic resonance imaging of bone marrow changes in Gaucher disease during enzyme replacement therapy: first German long-term results. Skeletal radiology 2001; 30: 496503

20 Robertson PL, Maas M, Goldblatt J. Semiquantitative assessment of skeletal response to enzyme replacement therapy for Gaucher's disease using the bone marrow burden score. Am J Roentgenol 2007; 188: $1521-1528$

21 Sether $L A, Y u$ S, Haughton VM et al. Intervertebral disk: normal agerelated changes in MR signal intensity. Radiology 1990; 177: 385-388

22 Malko JA, Hutton WC, Fajman WA. An in vivo magnetic resonance imaging study of changes in the volume (and fluid content) of the lumbar intervertebral discs during a simulated diurnal load cycle. Spine 1999; 24: $1015-1022$

23 Kingma I, van Dieen JH, Nicolay K et al. Monitoring water content in deforming intervertebral disc tissue by finite element analysis of MRI data. Magnetic resonance in: medicine official journal of the Society of Magnetic Resonance in Medicine / Society of Magnetic Resonance in Medicine 2000; 44: 650-654 